\title{
Comparative Evaluation of Some Physicochemical Properties on Selected Commercially Available Soaps on the Zambian Market
}

\author{
Christopher Mwanza*, Kadango Zombe \\ Department of Chemistry, School of Natural Sciences, University of Zambia, Lusaka, Zambia \\ Email: *christopher.mwanza@unza.zm, ${ }^{\star}$ chrismwanza@hotmail.co.uk
}

How to cite this paper: Mwanza, C. and Zombe, K. (2020) Comparative Evaluation of Some Physicochemical Properties on Selected Commercially Available Soaps on the Zambian Market. Open Access Library Journal, 7: e6147.

https://doi.org/10.4236/oalib.1106147

Received: February 7, 2020

Accepted: March 21, 2020

Published: March 24, 2020

Copyright $\odot 2020$ by author(s) and Open Access Library Inc.

This work is licensed under the Creative Commons Attribution International License (CC BY 4.0).

http://creativecommons.org/licenses/by/4.0/

\begin{abstract}
The Zambian market has witnessed an impressive upsurge in the production and consumption of a variety of soaps in recent years. However, there is scant, if any, knowledge of the quality and safety of these soaps. In this undertaking, the quality of some selected soaps was evaluated. The soap samples were randomly obtained from various supermarkets. The qualities of soaps were assessed based on the following physicochemical parameters: free caustic alkali (FCA), moisture content (MC), total fatty matter (TFM), $\mathrm{pH}$ and total alkali content (TAC). Upon analysis, a variation in these physicochemical properties was observed. Percent MC ranged between $6.70 \% \pm 0.06 \%$ and $18.13 \% \pm 0.13 \%$. Solo and Yebo recorded the highest MC. The $\mathrm{pH}$ values ranged from $10.70 \pm 0.02$ to $12.23 \% \pm 0.01 \%$. Yet again, Yebo had the highest $\mathrm{pH}$ followed by Solo and then Romeo. The TAC was between $2.00 \% \pm 0.06 \%$ to $2.40 \% \pm 0.01 \%$ and FCA values were from 0.00 to $0.021 \% \pm 0.00 \%$. Romeo had the highest TAC value $(2.40 \% \pm 0.01 \%)$ followed by Dettol $(2.31 \% \pm$ $0.05 \%)$. Only Solo and Yebo showed some traces of FCA. On the other hand, TFM values ranged from $51.60 \% \pm 0.60 \%$ to $78.15 \% \pm 1.66 \%$. Romeo recorded the highest TFM value $(78.15 \% \pm 1.66 \%)$ and Yebo recorded the lowest $(51.60 \% \pm 0.60 \%)$. On average, most soaps analysed herein were of fairly acceptable quality and are fit for use.
\end{abstract}

\section{Subject Areas}

Analytical Chemistry, Applied Sciences

\section{Keywords}

Soap, Total Fat Matter, Total Alkali Content, Moisture Content, pH, 


\section{Background, Scope and Aim}

"Cleanliness is next to godliness" is one popular adage extensively used in our societies in reinforcing the need and importance of keeping ourselves and our surroundings clean. In line with this aphorism, cleanliness could, therefore, imply a moral quality. Cleanliness may be described from an abstract standpoint as a state of being clean and free from dirt and the habit of achieving and maintaining that state. On a practical level, cleanliness is related to hygiene and disease prevention [1]. Washing is one way of achieving physical cleanliness, usually with water and often some kind of cleaning agent. With the intent of maintaining physical cleanliness regularly, an assortment of cleaning products is used in our everyday lives. These products safely and effectively remove soil, germs and other contaminants from our bodies, clothes, dishes and surroundings [2]. Soap, amongst many other products, is a typical example of a cleaning agent commonly used in enhancing beauty and maintaining physical cleanliness.

From a layman's perspective, soap can be described as any substance used usually in combination with water, to remove soil or greasy stuff from the skin, clothing, dishes, floors and walls. From the scientific standpoint, soap is a mixture of sodium or potassium salts of various naturally occurring fatty acids [3]. Now, fatty acids are not found in a free state in nature; commonly they exist in combination with glycerol (a trihydroxy alcohol) in the form of triglyceride. The structure of glycerol and triglyceride is shown in Figure 1. Fats and oils are called triglycerides (or triacylglycerols), because they are esters composed of three fatty acid units joined to glycerol [4]. Therefore, fats and oils are considered a source of fatty acids and it is for this reason that they are, to a great extent, employed in soap production.<smiles>CC(O)C(O)O</smiles>

glycerol

(a)

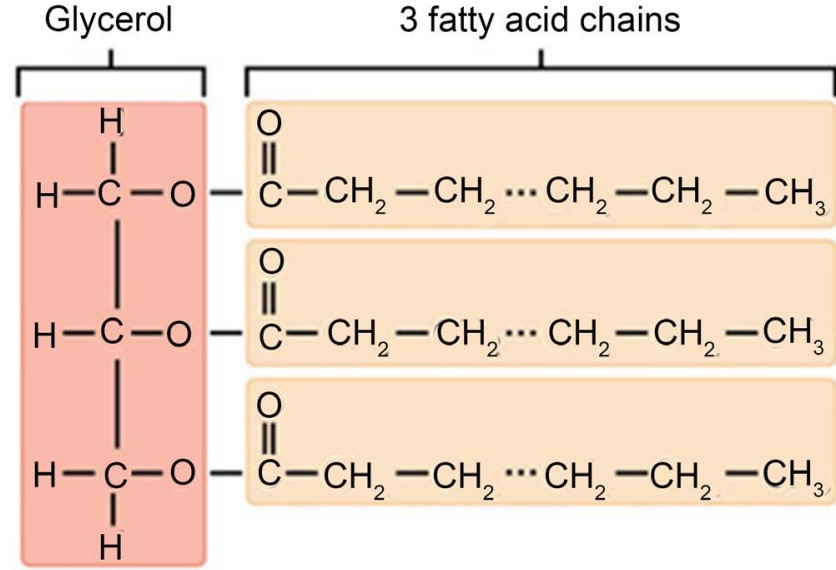

(b)

Figure 1. Structures of glycerol and triglyceride [5] [6]. 


\section{The Nature of Soap and its Manufacturing Process}

The potassium or sodium salt of fatty acids is the fundamental active agent present in all soap products. This active agent compound consists of a long hydrocarbon chain (composed of carbon and hydrogen atoms) with a carboxylic acid group at one end which is ionic as one oxygen atom is bonded to a metal ion, usually a sodium or potassium ion. The hydrocarbon end is non-polar and is soluble in non-polar substances (such as fats and oils), and the ionic end (the salt of a carboxylic acid) is soluble in water [7]. The structure of one type of soap molecule is represented in Figure 2. This molecule is an example of a primary component present in a soap product and the nature of the structure enables the soap to remove dirt from our bodies. A range of different types of soap products is commercially sold on the markets world over and come in various formulations including: bars, tablets, liquids, powder, pastes and flakes [8].

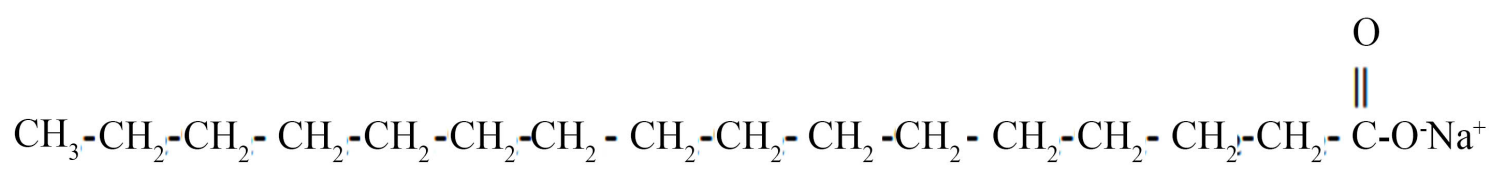

\section{Non-polar hydrocarbon chain (soluble in nonpolar substances)}

ionic end (soluble in water)

Figure 2. The structure of a soap molecule is adopted from David A. Katz [7].

Soap is typically produced from a hydrolysis reaction of a strong alkali (basic) reagent usually Sodium Hydroxide, $\mathrm{NaOH}$ (commonly known as caustic soda or lye), or Potassium Hydroxide, $\mathrm{KOH}$ (commonly known as caustic potash), with natural fats/oils (obtained from plants or animals) under controlled conditions in a process called saponification [9]. Regardless of the saponification reaction being depicted as a one-step reaction as illustrated below (Figure 3), it, in fact, involves two steps. Firstly, Triglycerides first undergo hydrolysis producing glycerol and fatty acid molecules. After that, the fatty acid portion is turned into a salt by reacting with a basic solution of the $\mathrm{NaOH}$. This salt of the fatty acid is precipitated out and is what is known as soap [10] [11]. The soap is then dried and pressed into bars (in the case of hard soap) [6].

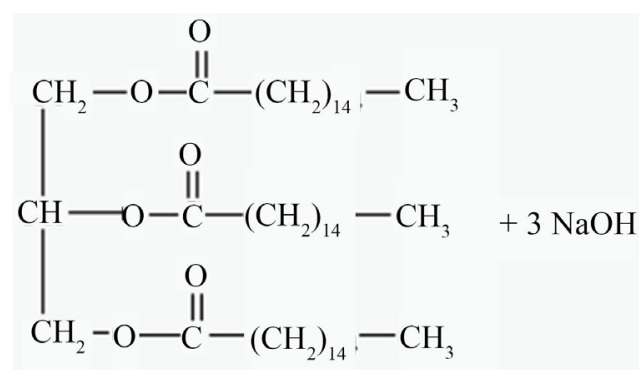

Triglyceride

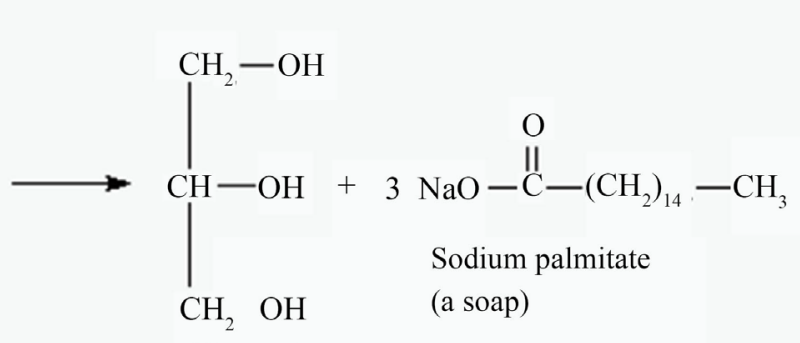

Glycerol

Figure 3. Saponification reaction of triglyceride (fat). 
Fat/oil $+\mathrm{NaOH} / \mathrm{KOH} \rightarrow$ glycerol + sodium/potassium salt of fatty acid [12]

Two forms of soap are obtained from the process depending on the alkali used. $\mathrm{NaOH}$ produces "hard soap" whereas $\mathrm{KOH}$ forms "soft soap" - hence used to make liquid soap. Nonetheless, both soaps are readily soluble in water, either cold or warm [11]. Several different types of fatty acids are used in soap production. However, palmitic, lyric, stearic (saturated fatty acids), linoleum and oleic acid (unsaturated fatty acids) are the types that are widely applied in the manufacture of soap [13] [14]. There is prevailing knowledge that a high-quality soap is obtained from a combination of fatty acids [14]. But to continuously produce high-quality soap, there is a need to be consistent in selecting the apposite oils/fats with their different fatty acids. Neverthless, some manufacturers produce soap of questionable quality partly due to utilization of oils/fats of low quality such as beef fat tallow. Most of these oils of low quality contain non-saponifiable fatty acids. A large amount of unsaponifiable fatty acids lower the quality of a soap product [14] [15]. A finished soap product is not exclusively composed of fatty acid salts; it also contains additives such as fillers, emollients, preservatives and many others in different proportions. These additives are used to lower its cost of production and/or confer a variety of special, unique properties of a respective soap product [11].

Quality control and standard assurance of any type of commercially produced consumables and non-consumable products, including soap products aids in keeping the citizenry safe and healthy. In recent times several articles have been published to address the issue of quality and safety of commercially produced soap around the globe [6] [16] [17] [18] [19] [20]. It is worth mentioning that poor quality soap has been implicated in many skin conditions such as acne, eczema, hives, rashes, skin irritation and possibly cancer [21]. Many authors contend that poor quality soap is as a result of poor methods of preparation and utter carelessness on the part of the manufacturers during the production stage [14] [19]. To guarantee compliance by manufactures to adhere to manufacturing products of acceptable quality, many countries have instituted standard regulatory boards such as the Zambia Bureau of Standards (ZABS), Bureau of Indian Standards (BIS), Standard Organization of Nigeria (SON), Uganda National Bureau of Standards (UNBS), Kenya Bureau of Standards (KEBS) and South African Bureau of Standards (SABS), etc, which are mandated to formulate standards for an array of products including soaps. At international and regional level, there organizations such as the International Standard Organization (ISO), American Oil Chemists Society (AOCS), East African Standards (EAS) and the African Organization for Standardization (ARSO) that set standards that a product must meet to be considered fit for consumption. Countries may as well adopt some of the developed standards or product analyses protocols developed by these international and regional organizations.

According to some selected peer-reviewed and published articles, a soap of satisfactory quality is one that strikes a balance in all the measurable physico- 
chemical (relates to physical and chemical characteristics) parameters which include but not limited to; Total Fat Matter (TFM), Free Caustic Alkali (FCA), Total Alkali Content (TAC), Moisture Content (MC), pH, etc., [12] [17] [20]. These physicochemical properties of soap determine their quality and cleansing efficacy [12]. To add on, these physicochemical characteristics of soap are affected by several factors which include the strength and purity of alkali used, the kind of oil/fat used and the completeness of the saponification reaction [20].

TFM is one of the most important characteristics describing the quality of soap. It is essentially a measure of identifying the amount of fatty matter present in soap [11] [14]. It is also described as the total amount of fatty matter, mostly fatty acids, that can be separated from a sample after splitting with a mineral acid, usually hydrochloric acid [22]. The latter description of TFM is actually the basis of the method employed in determining TFM in this paper. TFM value is reported as a percentage. A low TFM value is usually associated with hardness and lower quality of soap. By and large, soap with low TFM is a result of utilization of relatively large amounts of fillers during their production. Fillers, which are usually dry powders, tend to make soap harder and this makes it be harsh on the skin and when used in large amounts, fillers affect soap texture consequently making it to quickly get mushy when left in water for a specific period [14].

In older days in Europe and some countries now, soap with TFM 75\% minimum was referred to as Grade I and $65 \%$ minimum as Grade II. The soap with the higher TFM gives more lather, lasts longer and more importantly, cleans one's skin better and more gently. The least quality soap (Grade III) has to have at least $60 \%$ TFM [11]. The BIS categorizes toilet soaps into three grades based on the total fatty matter present in them. If TFM is beyond $76 \%$, it is classified as grade I and it has a very good quality. TFM above $60 \%$ fits to grade II and TFM above $50 \%$ fits to grade III [14]. For ZABS standard ZS 056 of 2009, a soap product must have a minimum value of 55\% for TFM. For MC and FCA, the maximum values are $25 \%$ and of $0.05 \%$ by mass respectively.

Latterly, Zambia has witnessed an impressive upsurge in the production and consumption of soap products [23]. The market has been "flooded" with a range of different types of soap products of which, there is scarce information vis-à-vis soap quality. Some soap sold directly to consumers may have been made to the manufacturers' formulations and specifications rather than to any official standard quality specifications. Notwithstanding this, any product should meet certain specific standards set by respective national or international standards bodies. As a consequence, the need for constant quality surveillance on the commercially available soap products sold in the open markets is of extreme importance [6] [24]. Herein, we report the measurable physicochemical properties of a selection of soaps available on the Zambian market. At the time of this investigation and to the best of our knowledge, there wasn't any published article that had reported on the physicochemical properties of soap products available on the Zambian market. 


\section{Materials and Methods}

\subsection{Equipment and Reagents}

Analytical balance (Ohaus, scout pro SPU202), $\mathrm{pH}$ meter (Crison base 20), oven (Memmert model 500), distillation apparatus, distilled water, petroleum ether, sodium hydroxide $(0.5 \mathrm{~N})$, methyl orange indicator, phenolphthalein indicator, nitric acid $(0.5 \mathrm{~N})$, oxalic acid $(0.25 \mathrm{M})$, Sulphuric acid $(0.05 \mathrm{~N})$, sodium carbonate $(0.05 \mathrm{~N})$, anhydrous sodium sulphate, $\mathrm{pH}$ buffers (4, 7 and 9) and distilled ethanol $(95 \% \mathrm{w} / \mathrm{w})$. All chemicals were of analytic grade and were obtained from reputable manufacturers.

\subsection{Sample Collection and Preparation}

Eight different soap samples were acquired from different supermarkets around Lusaka, Zambia. Three bars of each soap brand were procured. Soap samples were randomly selected, that is, no criterion was employed in selecting which soap samples to be analyzed. The samples were removed from the plastic covers and reduced into smaller pieces with the aid of a grater. Then they were thoroughly mixed to obtain a homogeneous sample; a representative of the samples purchased. Grated samples were kept in airtight glass containers filled to capacity so that there is no headspace. The samples were then stored at a temperature of $4^{\circ} \mathrm{C}$ until when required for them to be subjected to specific rigorous laboratory operations as described below. Each parameter was then measured in triplicate.

\subsection{Analysis of the Physicochemical Properties of Soaps}

\subsubsection{Moisture Content}

Moisture content was determined as described in [20] which is also a standard procedure prescribed by AOCS [17] with some minor modifications. $5.00 \mathrm{~g}$ of the sample was weighed in a dry and tarred crucible and placed in the oven at $103^{\circ} \mathrm{C} \pm 2{ }^{\circ} \mathrm{C}$ for $2: 30 \mathrm{hrs}$. The crucible plus sample was allowed to cool in a desiccator and then re-weighed. The percent moisture content was determined by employing the following formula:

$$
\% \text { Moisture content }=\frac{C s-C h}{C s-C w} \times 100
$$

where;

$$
\begin{aligned}
& C W=\text { weight of the crucible } \\
& C s=\text { weight of crucible }+ \text { sample } \\
& C h=\text { weight of crucible + sample after floating. }
\end{aligned}
$$

\subsection{2. $\mathrm{pH}$}

The $\mathrm{pH}$ was determined as described in [20] with very minor modifications. 2.00 $\mathrm{g}$ of soap was dissolved in $20 \mathrm{ml}$ distilled water to make a $10 \%$ soap solution. Then the solution was left to stand overnight to allow the complete dissolution of soap. The $\mathrm{pH}$ was measured with a $\mathrm{pH}$ meter on the following day. 


\subsubsection{Total Fatty Matter}

Total fatty matter and Total alkali content were determined as described in [11] with some minor modifications. $5.00 \mathrm{~g}$ of the sample was weighed and dissolved in $100 \mathrm{ml}$ of $50 \% \mathrm{v} / \mathrm{v}$ ethanol. Then the mixture was heated on the water bath until the entire sample had been dissolved and while the solution was still hot, 40 $\mathrm{ml}$ of $0.5 \mathrm{~N}$ nitric acid was added followed by vigorous shaking. The solution was then left to cool at room temperature and transferred in a separatory funnel. The fatty acids were extracted with two portions of $50 \mathrm{ml}$ and $25 \mathrm{ml}$ petroleum ether. The two organic portions were then combined and dried by using anhydrous sodium sulphate to remove any traces of water and evaporated on a tarred crucible. The remaining aqueous layer was kept for determination of total alkali content while the total fatty matter was determined using the following formula:

$$
\% \text { fatty matter }=\frac{Y-X}{W S} \times 100
$$

where:

$$
\begin{aligned}
& Y=\text { weight of crucible }+ \text { sample after evaporation } \\
& X=\text { weight of empty crucible } \\
& W s=\text { weight of sample }
\end{aligned}
$$

\subsubsection{Total Alkali Content}

Total alkali content was determined as follows; $5.00 \mathrm{~g}$ of the sample was weighed and dissolved in $100 \mathrm{ml}$ of $50 \%$ ethanol. Then the mixture was heated on the water bath until the entire sample had been dissolved and while the solution was still hot, $40 \mathrm{ml}$ of $0.5 \mathrm{~N}$ Nitric acid was added followed by vigorous shaking. The solution was left to cool to room temperature and transferred in a separatory funnel. The fatty acids were then extracted with two portions of $50 \mathrm{ml}$ and $25 \mathrm{ml}$ petroleum ether leaving the aqueous layer. The total volume of the aqueous layer was measured with a measuring cylinder and a $10 \mathrm{ml}$ portion from this was titrated with standardized $\mathrm{NaOH}$ using methyl orange as indicator. The total alkali content was determined using the following formula.

$$
\% \text { of alkalinity }=\frac{Y \times 100}{W}
$$

where: $Y$ is the alkalinity factor obtained by a mathematical expression described by [11].

$$
W=\text { weight of sample }
$$

\subsubsection{Free Caustic Alkali}

Free caustic alkali was determined as described by [18]. Consistent with this prescribed method, $2.5 \mathrm{~g}$ samples were dissolved in $15 \mathrm{ml}$ distilled ethanol and heated in the water bath until the sample had completely dissolved. This was followed by the addition of about 5 drops of phenolphthalein indicator and $5 \mathrm{ml}$ of $20 \% \mathrm{BaCl}_{2}$. The resultant solution was titrated against $0.05 \mathrm{M} \mathrm{H}_{2} \mathrm{SO}_{4}$, to the disappearance of pink colour. The free caustic alkali was calculated using the formula: 


$$
\text { Free Caustic Alkali }=\frac{0.31 \times V a}{W}
$$

where:

$$
\begin{aligned}
& V a=\text { volume of acid } \\
& W=\text { weight of sample }
\end{aligned}
$$

\section{Results and Discussion}

In this paper, a total of five parameters to determine the physicochemical properties of some soaps on the Zambian market were analyzed. The results of the physicochemical properties of the soap samples are recorded in Table 1 below. Moisture content (MC) was the first parameter to be determined. MC is a measure of the amount of free water present in the soap. It is an important parameter used to determine the shelf life of soap [16]. Excess water in soap reacts with any unreacted triglycerides (Fats/Oils) which might be present in soap, that is, they undergo hydrolysis to form fatty acids and glycerol on storage [17]. Thus, superfluous water would undoubtedly affect the quality of soap and certainly reduce its shelf life.

Table 1. Physicochemical properties of selected commercial soaps in Zambia.

\begin{tabular}{cccccc}
\hline $\begin{array}{c}\text { Commercial } \\
\text { name of the soap }\end{array}$ & $\begin{array}{c}\text { Moisture } \\
\text { Content (\%) }\end{array}$ & $\mathrm{pH}$ & $\begin{array}{c}\text { Total Alkali } \\
\text { Content (\%) }\end{array}$ & $\begin{array}{c}\text { Free caustic } \\
\text { Alkali (\%) }\end{array}$ & $\begin{array}{c}\text { Total Fatty } \\
\text { Matter (\%) }\end{array}$ \\
\hline Romeo & $10.33 \pm 0.07$ & $11.37 \pm 0.02$ & $2.40 \pm 0.01$ & $0.00 \pm 0.00$ & $78.15 \pm 1.66$ \\
Dettol & $8.67 \pm 0.07$ & $11.15 \pm 0.03$ & $2.31 \pm 0.05$ & $0.00 \pm 0.00$ & $65.40 \pm 1.06$ \\
Solo & $18.13 \pm 0.13$ & $11.49 \pm 0.02$ & $2.00 \pm 0.06$ & $0.0037 \pm 0.00$ & $61.50 \pm 0.10$ \\
Protex & $8.50 \pm 0.10$ & $10.70 \pm 0.02$ & $2.13 \pm 0.01$ & $0.00 \pm 0.00$ & $70.80 \pm 1.80$ \\
Yebo & $18.10 \pm 0.08$ & $12.23 \pm 0.01$ & $2.18 \pm 0.05$ & $0.021 \pm 0.00$ & $51.60 \pm 0.60$ \\
Mediherb & $10.70 \pm 0.08$ & $11.31 \pm 0.03$ & $2.24 \pm 0.04$ & $0.00 \pm 0.00$ & $73.10 \pm 0.10$ \\
Lifebuoy & $12.20 \pm 0.00$ & $11.10 \pm 0.04$ & $2.03 \pm 0.01$ & $0.00 \pm 0.00$ & $63.40 \pm 0.90$ \\
Lux & $6.70 \pm 0.06$ & $11.06 \pm 0.02$ & $2.32 \pm 0.05$ & $0.00 \pm 0.00$ & $74.5 \pm 1.22$ \\
\hline
\end{tabular}

From the data collected it was found that the percent $\mathrm{MC}$ of the soap ranged from $6.70 \% \pm 0.06 \%$ to $18.13 \% \pm 0.13 \%$. From this study, we found out that Solo and Yebo had the highest MC of $18.13 \% \pm 0.13 \%$ and $18.10 \% \pm 0.08 \%$ respectively. On the other hand, Lux had the lowest MC of $6.70 \% \pm 1.49 \%$. Further, the percent MC for Romeo $(10.33 \% \pm 1.12 \%)$, Mediherb $(10.70 \% \pm 1.32 \%)$ and lifebuoy $(12.20 \% \pm 0.0 \%)$ were within limits set by the Encyclopaedia of Industrial Chemical Analysis (EICA) of 10\% - 15\% [18]. Whereas the values for Dettol, Protex and Lux $8.67 \% \pm 1.33 \%, 8.50 \% \pm 1.66 \%$ and $6.70 \% \pm 1.49 \%$ respectively were lower than the EICA standards. However, most of the soap analyzed will not provide a conducive environment for the growth of microbes since they are within the recommended moisture content of $10 \%-20 \%$ [25]. Low MC for Lux could be due to a prolonged time difference from the time the soaps were 
manufactured to the day they were purchased for analysis. Overall, the percent MC values determined in all the soaps were within acceptable limits; they are also below that which is recommended by ZABS (ZS 056) of which the maximum should be $25 \%$ by mass for total moisture and volatile matter.

$\mathrm{pH}$ was the next parameter to be determined. $\mathrm{pH}$ is the measure of the acidity or alkalinity of a substance [2]. $\mathrm{pH}$ is also a significant parameter in determining the quality of soap. Soap with $\mathrm{pH}$ values below 5 and those with $\mathrm{pH}$ way above 10 are associated with harshness on the hands and skin [2] [8]. Conversely, it must be noted that soap is naturally a salt of a weak acid (fatty acid) and a base. Hence, it is alkaline in aqueous solution; as a result, soap is generally expected to have a $\mathrm{pH}$ above 7 . In the present study, the determined $\mathrm{pH}$ values were between $10.70 \pm 0.02$ and $12.23 \pm 0.01$. Of all the soap samples analyzed, Yebo had the highest $\mathrm{pH}(12.23 \pm 0.01)$, followed by Solo (11.49 \pm 0.02$)$, then Romeo (11.37 \pm $0.02)$ and Mediherb (11.31 \pm 0.03$)$. Dettol and Lifebuoy had $\mathrm{pH}$ values of $11.15 \pm$ 0.03 and $11.10 \pm 0.04$ respectively. Protex recorded the lowest $\mathrm{pH}$ value of 10.70 \pm 0.02 . Soap with very high $\mathrm{pH}$ (highly alkaline) indicates that they may be corrosive to the skin. Strongly alkaline cleansing products tend to neutralize the body's protective acid mantle that acts as a barrier against bacteria and viruses [17]. Healthy skin has a pH of 5.4 to 5.9 [26]. Generally, $\mathrm{pH}$ values obtained in this work were slightly higher than those obtained by [20] but, similar to what [6] obtained. Further, the values obtained in this probe were above the BIS stipulated range of $(7-10)$. Relatively high values observed in some soaps may be an indication of incomplete alkali hydrolysis resulting from the saponification process. Higher $\mathrm{pH}$ values in soap products can be overcome or controlled by the addition of excess fat/oil (supperfatting) in acceptable amounts or application of $\mathrm{pH}$ adjusters to reduce its harshness and corrosiveness on the skin [2] [27].

The total alkali content (TAC) is the other parameter that was determined. It represents the amount of total alkaline component in soap. It includes alkaline compounds such as sodium/or potassium hydroxides, oxides, carbonates or bicarbonates [17]. According to the BIS, good quality soap must have less than 5\% of TAC whereas, for the ISO specification, soap should have amounts below $2 \%$ of TAC [11]. In the current study, the determined TAC was between $2.40 \pm 0.01$ and $2.00 \pm 0.06$. These values were comparable to those obtained by [11] which were in the range of 2.96 to 1.61 . However, they were higher than the $0.2 \%$ standard value set by the EAS but, comparable to the $2 \%$ specified in the ISO.

Free Caustic Alkali (FCA) was also determined. Principally, FCA content determines the abrasiveness of the soap. Superior soap should contain little or no free alkali [24]. Soap with an excess amount of FCA irritates the skin and wear-out clothes [26]. Alkaline soaps are characterised by a high content of FCA can lead to skin dryness and scaling which cause the skin becomes susceptible to fungal attacks. This is because the excess alkali will saponify the fats and oils that are normally found on the skin as a protective coat to form soluble soap and therefore get washed away thereby rendering the skin dry [24]. The recom- 
mended FCA content of soap by the EAS is less than $0.1 \%$. In the current investigation, all the soaps had no FCA except for Yebo and Solo which showed some presence of traces FCA amounting to $0.021 \%$ and $0.0037 \%$ respectively. Nonetheless, these amounts of FCA that was present in Solo and Yebo were less than the set of the EAS $(0.2 \%)$ and that set by ZABS (maximum should be $0.05 \%$ ). However, it is also worth noticing that these very two soaps (Yebo and Solo) that had some traces of FCA also had the highest $\mathrm{pH}$ values. But then again, the FCA values determined do not call for any concern.

As earlier stated, total fatty (or simply fat) matter (TMF) is the most important parameter in determining the quality of soap; in this study, it was, therefore, also determined. The IOS and EAS standard for toilet soap is 76\%. [11]. In the current study, TMF values ranged from $51.60 \% \pm 0.06 \%$ to $78.56 \% \pm 1.66 \%$. Romeo had the highest TMF value of $78.56 \% \pm 1.66 \%$ followed by Lux $(74.5 \% \pm$ $1.22 \%)$, Mediherb $(73.10 \% \pm 0.10 \%)$ and then Protex with TFM of $70.80 \% \pm$ $1.80 \%$. On the other, hand Yebo and Solo had the least amounts of $51.60 \% \pm$ $0.60 \%$ and $61.50 \% \pm 0.10 \%$ respectively. Dettol and Lifebouy had medium values $65.40 \% \pm 1.06 \%$ and $63.40 \% \pm 0.90 \%$. The TFM values for $\operatorname{Lux}(74.5 \% \pm 1.22 \%)$, Dettol $(65.40 \% \pm 1.06 \%)$ and Lifebuoy $(63.40 \% \pm 0.90 \%)$ obtained in this work were lower than those obtained by [20] whose values were as follows; Lux (85.10 $\pm 0.01)$, Dettol $(100 \pm 0.00)$ and Lifebuoy $(87.23 \pm 0.04)$ [20]. On the other hand, values for Lux and Dettol obtained in the current undertaking were significantly higher than those obtained by [6] for which Lux total fatty matter was $35.00 \%$ and for Dettol was $15 \%$. The discrepancy could be due to different methods of analysis or method of soap production in different regions; however, this was not confirmed. What's more, in this assessment, it was observed that colorants and other constituents in soap can contribute to the determined TFM value because some solvents such as chloroform, would also extract these additives during TFM determination. It is for this reason we elected to utilize petroleum ether for extraction purposes. In this regard, it is strongly recommended that certain procedures which employ solvents that do not remove these additives should be avoided when determining TFM otherwise the reported TMF value might not be the true reflection of the actual value.

\section{Conclusion}

The obtained results showed a variation in the physicochemical properties of the analyzed soap. To some extent, Solo and Yebo presented the most variation in terms of physiochemical properties from the other soap. Their moisture contents were higher than any of the other soap analysed. Besides, their TFM values were also lower compared to the other soap samples. However, these results were acceptable for bar soap and not for toilet soap. With an exception for Romeo soap, with TMF of $78.56 \% \pm 1.66 \%$, the rest of the soaps had TMF values less than the BIS and EAS standard for toilet soap. Under the BIS, Solo, Mediherb, Protex, Lux, Lifebouy and Dettol can hence, be classified as grade II while Yebo as grade 
III. Other parameters which include moisture content, free caustic alkaline and total alkali content were within the limit for good quality soap. On average, the soaps analysed were of acceptable quality and are fit for use.

\section{Recommendations}

Irrespective of the fact that soaps analysed here have been determined to be of a fairly acceptable standard, we would like to recommend that another study on a larger scale, analysing as many different soaps as possible, with an inclusion of many other parameters be carried out. This will certainly be more conclusive and give an even clearer picture of the quality of soaps that the Zambian consumers are subjected to. Further, we are of the opinion that ZABS should update the standard so that it caters for more parameters to be met for a soap to be on the Zambian market. The ZS 056 standard only provides for four parameters that a soap product is required to meet for it to be considered fit for the consumers. In the current state, we feel a room has been created for the market to be flooded with inferior soap products. Finally, it is worth asserting that excessive and frequent use of any regular soap (as well as other cleansing products) may result in increased skin dryness and tautness, especially when applied to the face during the cold and dry season and in individuals with dry, sensitive skin [28]. Thus, we urge sagacious use of these cleaning products; keep your skin healthy by choosing the right soap for your skin; select a soap that keeps a balance among the physicochemical properties discussed.

\section{Acknowledgements}

We would like to wholeheartedly thank the chemistry department headed by Dr. M.O Munyati for providing us a conducive environment to carry out our study. Specific gratitude goes to Mr. George Chikonde who was the acting chief scientist at the time this survey was conducted.

\section{Conflicts of Interest}

No conflict of interest has been declared by the authors.

\section{References}

[1] Specifications: Cleaning Material and Toiletries. https://etenders.treasury.gov.za/sites/default/files/tenders/Specifications $\% 20$ for $\% 20 \mathrm{t}$ oiletries\%20and\%20cleaning\%20material.pdf

[2] American Cleaning Institute (2019) The Science of Soap: An Introduction to the Science of How Things Get Clean.

https://www.cleaninginstitute.org/sites/default/files/assets/1/AssetManager/Science ofSoap.pdf

[3] Warra, A., Hassan, L., Gunu, S. and Jega, S. (2011) Cold-Process Synthesis and Properties of Soaps Prepared from Different Triacylglycerol Sources. Nigerian Journal of Basic and Applied Sciences, 18, 315-321.

https://doi.org/10.4314/njbas.v18i2.64350 
[4] T.E. of E. Britannica. No Title. https://www.britannica.com/science/fatty-acid

[5] Simple Lipids-Fats, Oils and Waxes. https://alevelbiology.co.uk/notes/simple-lipids-fats-oils-waxes/

[6] Idoko, O., Emmanuel, S.A., Salau, A.A. and Obigwa, P.A. (2018) Quality Assessment on Some Soaps Sold in Nigeria. Nigerian Journal of Technology, 37, 1137. https://doi.org/10.4314/njt.v37i4.37

[7] Katz, D.A. (2000) The Science of Soaps and Detergents. https://www.coursehero.com/file/14486561/Soap-and-detergent/

[8] Warra, A.A. (2013) A Report on Soap in Nigeria Using Indigenous Technology and Raw Materials. African Journal of Pure and Applied Chemistry, 7, 139-145. https://doi.org/10.5897/AJPAC11.016

[9] Osagie, O.F. (2015) Utilization of Agricultural Waste (Rubber Seed Oil, Kolanut Pods and Almond Leaves) for Soap Production. International Journal of Geography and Environmental Management, 1, 121-135.

[10] Zauro, S.A., Abdullahi, M.T., Aliyu, A., Muhammad, A., Abubakar, I. and Sani, Y.M. (2016) Production and Analysis of Soap Using Locally Available Raw-Materials. Applied Chemistry, 96, 41479-41483.

[11] Betsy, K.J., Jilu, M., Fathima, R. and Varkey, J.T. (2013) Determination of Alkali Content \& Total Fatty Matter in Cleansing Agents. Asian Journal of Science and Applied Technology, 2, 8-12.

[12] Mohammed, U.F. and Usman, A. (2018) Physico-Chemical Analysis of Some Soaps Produced from Five Locally Processed Nigerian Oils. International Journal of Scientific and Engineering Research, 9, 531-539.

[13] Mishra, D. (2002) Preparation of Soap Using Different Types of Oils and Exploring Its Properties Submitted by Debesh Mishra Department of Chemical Engineering National Institute of Technology Under the guidance of Dr. Susmita Mishra. Journal of the American Oil Chemists' Society, 6, 185-192.

[14] Arasaretnam, S. and Venujah, K. (2019) Natural Products Chemistry \& Preparation of Soaps by U Sing Different Oil and Analyze Their Properties. Natural Products Chemistry and Research, 7, 1-4.

[15] Sharma, H., Giriprasad, R. and Goswami M. (2013) Animal Fat-Processing and Its Quality Control. Journal of Food Processing \& Technology, 4, 252. https://doi.org/10.4172/2157-7110.1000252

[16] Popescu, V., Soceanu, A., Dobrinas, S., Stanciu, G. and Epure, D.T. (2011) Quality Control and Evaluation of Certain Properties for Soaps Made in Romania. Scientific Study \& Research: Chemistry \& Chemical Engineering, Biotechnology, Food Industry, 12, 257-261.

[17] Vivian, O.P., Nathan, O., Osano, A., Mesopirr, L. and Omwoyo, W.N. (2014) Assessment of the Physicochemical Properties of Selected Commercial Soaps Manufactured and Sold in Kenya. Open Journal of Applied Sciences, 4, 433-440. https://doi.org/10.4236/ojapps.2014.48040

[18] Abulude, F., Fagbayide, S.D., Olubayode, S.A. and Adeoya, E.A. (2017) Assessment of Physicochemical Properties of Soaps, Detergents and Water Samples Originated from Nigeria. Continental Journal of Sustainable Development, 8, 55-67.

[19] Amponsah, D., Sebiawu, G.E. and Nagai, H. (2014) Quality Analysis of Selected Liquid Soaps in Ghana. International Journal of Advanced Research and Technolo$g y, 3,124-128$.

[20] Habib, A., Kumar, S., Sorowar, S., Karmoker, J., Khatun, M.K. and Al-Reza, S.M. 
(2016) Study on the Physicochemical Properties of Some Commercial Soaps Available in Bangladeshi Market. International Journal of Advanced Research in Chemical Science, 3, 9-12. https://doi.org/10.20431/2349-0403.0306002

[21] Poucher, W.A. (1993) Perfumes, Cosmetics and Soaps. https://doi.org/10.1007/978-94-011-1484-4

[22] Hare, L.B. (2002) Chapter One. Quality Progress-Though the Scientific Method Is Fundamental to Science and Business It Is Often Misused, Overlooked or Abandoned. Quality Progress, 35, 77-79.

[23] Bosiu, T., Chinanga, F., Das Nair, R., Mondliwa, P., Phiri, M. and Ziba, F. (2018) Growth and Development in the Cosmetics, Soaps and Detergents Regional Value Chains: South Africa and Zambia. SSRN Electronic Journal. https://doi.org/10.2139/ssrn.3020542

[24] Nangbes, J.G., Zukdimma, N.A., Wufem, B.M., Lawam, T.D. and Dawam, N.N. (2014) Quality Survey and Safety of Some Toilet Soaps in the Nigerian Market: A Case Study of B/Ladi, Bokkos and Pankshin, Plateau State. IOSR Journal of Applied Chemistry, 7, 29-35. https://doi.org/10.9790/5736-07732935

[25] Caetano, J.A., Lima, M.A., Miranda, M.D.C., Serufo, J.C. and Ponte, P.R.L. (2011) Identification of Bacterial Contamination in Liquid Soap for Hospital Use. Revista da Escola de Enfermagem da US P, 45, 148-155. https://doi.org/10.1590/S0080-62342011000100021

[26] Firempong, E. and Mak-Mensah, C.K. (2011) Chemical Characteristics of Toilet Soap Prepared from Neem (Azadirachta indica A. Juss) Seed Oil. Asian Journal of Plant Science and Research, 1, 1-7.

[27] Warra, A.A., Atiku, F.A., Wawata, I.G. and Gunu, S.Y. (2011) Soap Preparation from Soxhlet Extracted Nigerian Cotton Seed Oil. Advances in Applied Science Research, 2, 617-623.

[28] Yarovoy, Y. and Post, A.J. (2016) Soap Bar Performance Evaluation Methods. 2nd Edition, Volume 1941, Elsevier Ltd., New York. https://doi.org/10.1016/B978-1-63067-065-8.50011-6 